\title{
The Role of Grandparental Sensitivity and Parental Sensitivity in Infant Cognitive Development in China: A Pilot Study
}

\author{
Wei Li ${ }^{1}{ }^{1} \cdot$ Rosanneke Emmen $^{1} \cdot$ Mi-lan Woudstra ${ }^{1} \cdot$ Marjolein Branger $^{1} \cdot$ Lamei Wang $^{2} \cdot$ Lenneke Alink $^{1} \cdot$ \\ Judi Mesman ${ }^{1}$
}

Accepted: 5 December 2021 / Published online: 25 January 2022

(c) The Author(s) 2022

\begin{abstract}
Grandparental caregiving is common in China, which can directly impact grandchild development. In addition, grandparents may have an indirect impact on children through their relationship with and support of the parents. However, associations between grandparenting, parenting, and child outcomes are rarely investigated. The current study is a pilot study which includes 42 mothers, fathers, and co-residing grandparents in China, and examines whether grandparental sensitivity relates to parental sensitivity (biological child of the grandparent), and whether grandparental sensitivity and maternal and paternal sensitivity each uniquely contribute to 14-month-old children's Executive Function (EF). Results did not show a significant relation between parental and grandparental sensitivity or a unique contribution of sensitivity from mothers, fathers, or grandparents to infant EF. Our findings from exploratory analyses showed differences in sensitivity of grandparents and parents towards the third generation but did not confirm a combined effect of multiple caregivers on infant EF development in China.
\end{abstract}

Keywords Sensitivity $\cdot$ Grandparents $\cdot$ Mothers and fathers $\cdot$ Infant EF $\cdot$ China

\section{Highlights}

- This pilot study is the first to observe caregiving in mothers, fathers and co-residential grandparents in China.

- The study investigated the relation between grandparenting and parenting, and the association of multiple caregiving with infant EF development.

- Sensitivity levels of grandparents towards the third generation were lower than those of parents.

- There was no significant combined effect of multiple caregivers (mother, father and grandparent sensitivity) on infant EF development.

This paper has not been published or accepted for publication and it is not under consideration at another journal. All authors have seen and reviewed the paper and are in agreement with the contents of the manuscript. The study

Wei Li

w.li@fsw.leidenuniv.nl

1 Institute of Education and Child Studies, Leiden University, Pieter de la Court, Wassenaarseweg 52, 2333 AK Leiden, The Netherlands

2 College of Psychology, Shenzhen University, 3688 Nanhai Ave, Nanshan Qu, Shenzhen Shi, Guangdong Sheng 518060, China was conducted in accordance with ethical standards of the American Psychological Association.

Three generations living under the same roof is common in Chinese society. Grandparents not only help with housework, but also function as joint parental caregivers in raising young children, and therefore may have both indirect and direct impact on child development. The indirect effect of grandparents (G1) on grandchildren (G3) can take place through parents (G2) in two ways. First, G1 supports G2 who can then be more attentive parents to G3 which positively influences G3 development (Chen et al., 2000). Second, G2 may parent the young children based on their own experience with G1 (e.g., Belsky et al., 2005). Grandparents may also have a direct effect on G3 development through their daily interactions with their 
grandchildren. However, associations between grandparenting, parenting, and child outcomes are rarely investigated. The current pilot study examines G1 and G2 parenting quality (specifically sensitive responsiveness) on G3 development (specifically Executive Function - EF) in families with 14-month-old children in urban China.

Different from the elderly in most of the Western countries where independent living is highly valued, Chinese grandparents are expected to play a major role in taking care of grandchildren (Burnette et al., 2012). The involvement of both co-residing and non-coresiding grandparents in childcare is a common experience in many Chinese families (Chen et al., 2011; Wang et al., 2019). Letting G3 grandparents live together with G2 parents is a good way to show filial piety and family solidarity which assumes family members are responsible for taking care of elderly people at home. Moreover, unlike the welldeveloped care systems and social welfare in many Western countries, China is still developing care facilities for the increasing aging population and social welfare system. Aging people still need care and financial support from their adult children to some extent. Ko and Hank (2013) found that among 772 Chinese families around $58 \%$ of grandparents are involved in daily childcare of their grandchildren. The reasons for a high prevalence of grandparenting in China can often be found in social and economic factors. Chinese women's labor force participation is the highest in the Asian Pacific region with limited flexibility in the work arrangement, especially in waged jobs (The World Bank, 2018). Working part-time is generally impossible as labor supply exceeds demand (e.g., Chen et al., 2011). Moreover, there is a shortage of daycare facilities, especially for children under 3 years of age (e.g., Zhai \& Gao, 2010). Given all of this, help from grandparents is the main reason that parents can maintain their paid jobs and balance work and childcare (Goh \& Kuczynski, 2010). In addition, the current early retirement age for women (50-55 years) and men (60 years) makes grandparental childcare possible (Feng and Zhang, 2017).

Grandparental involvement in childrearing of the third generation may have a positive impact on all generations (Barnett et al., 2010). First, G1 may be more active in social activities which may help them increase a sense of meaning during old age. Second, G1 involvement can relieve G2 from their full-time household work role besides their employment work. Moreover, support from G1 can reduce G2's stress and burden which is beneficial for G2's mental health and G3 child development. For example, due to the financial, emotional, and instrumental support of G1, G2 parents can have more free time and experience less stress when they interact with and educate G3 children which can enhance parent-child relationships and contribute to positive child outcome (Dunifon, 2012). Third, G1 can be a role model for G3 and help G3 to solve problems, and support G3's development. Thus, G1 grandparental caregiving can directly and indirectly influence G3 children's development. The impact of G1 parenting on G3 is possibly through G2 parenting as it is likely to be influenced by their own childhood experiences being parented by G1 (e.g., Conger et al., 2009; Chen et al., 2008). For example, mothers who experienced a positive family atmosphere and had more trusting, communicative relationships with their parents were more likely to show more warm-sensitive parenting. Sensitivity refers to caregivers' capability to accurately interpret the child's signals, and to respond to them promptly and appropriately (Ainsworth, 1964; Mesman \& Emmen, 2013), to their own young children (Belsky et al., 2005). Another possibility is that G2 parents may follow G1 grandparents' current behaviors on how to take care of G3 grandchildren as grandparents have more experience with young children in general. In China, this imitation may happen more often as parents are likely to show respect and adopt grandparents' advice due to the traditional value of filial piety (Yeh et al., 2013).

To date, relatively few studies on the concurrent relation between grandparenting and parenting have been conducted in mainland China especially for responsive-sensitive parenting even though caregiving grandparents are very common there. Three studies focused on warm, responsive-sensitive parenting in two generations in mainland China (He et al., 2020; Li et al., 2019; Xing et al., 2016). Based on children's reports (average 12 years old) on their perceived relationships with parents and grandparents, Li and colleagues (2019) found that grandparental care and autonomy were positively related to both mothers' and fathers' care and autonomy respectively. The other two studies focused on young children. One study showed that reported emotional warmth of G1 grandparents was associated with reported warmth of G2 parents towards G3 children aged 6-24 months in rural China (He et al., 2020). Another study showed that grandmaternal sensitivity towards their 17-month-old grandchild was positively related to maternal sensitivity towards the same child. However, these studies either used self-reported data from children or parents (He et al., 2020; Li et al., 2019), or in one of the studies it was not clear whether the participating G1 grandmothers had blood relations with G2 mothers (Xing et al., 2016). As observational studies may give a more objective picture of parental behaviors compared to questionnaire results, and it is important to know the association between grandparental behaviors and their biological children's behaviors, the current study measured grandparental and parental behaviors using an observational assessment, and focused specifically at biological grandparent-parent links.

As co-resident grandparents interact frequently with the third generation, G1 grandparents may have a direct impact on G3 grandchildren through child rearing, for example 
during feeding, reading, and playing or when grandparents support grandchildren in completing a task or solving problems (Dunifon, 2012). A recent systematic review by Sadruddin and colleagues (2019) showed that at the global level, grandparents can have an impact on children's physical and socio-emotional health as well as cognitive development in multigenerational families. In China, grandparents are not only involved in child care, but also provide home education to their grandchildren (Nyland et al., 2009). Grandparents' childrearing beliefs point towards an emphasis on physical health and nutrition (e.g., Jiang et al., 2007; Li et al., 2017) and schooling (Zeng \& Xie, 2014). One study conducted with 300 preschoolers in Chinese multiple-generational families showed that grandparental involvement facilitates children's social skills and reduces internalizing and externalizing behavioral problems but this relation is moderated by children's approach or withdrawal tendencies which means only children tending to withdraw instead of approach benefited from grandparental involvement. Grandparents may also help with reducing parental stress for children (Luo et al., 2020). The harmonious parent-grandparent coparenting relationship can also contribute to social competence among preschoolers' (Li \& Liu, 2019). Moreover, Chinese adolescents who had close relationships with paternal grandparents reported better bonding to school (i.e., feelings of connection with the school, teachers and classmates) and more positive self-evaluation (Liu, 2016). Bonding to paternal grandparents also buffered the negative effect of harsh parental discipline on delinquency on Chinese adolescents (mainly among boys; Liu, 2019). However, children raised by grandparents in China were more likely to be overweight or obese (Li et al., 2017).

An important aspect of early childhood development is the development of Executive Function (EF) which is an umbrella term underlining complex cognitive processes that include goal-directed actions such as inhibitory control, working memory and cognitive flexibility (Miyake et al., 2000; Zelazo et al., 1997). EF emerges as early as in the first year of life (Best et al., 2011) and is critical for later academic achievement (e.g., Sulik et al., 2018), better language development (e.g., Müller et al., 2009), better motor performance (e.g., Livesey et al., 2006) and fewer behavioral problems (e.g., Hughes \& Ensor, 2011). Parental sensitivity is a central dimension of parenting that has been shown to have an impact on EF development (e.g., Cabrera et al., 2011). Sensitive parents are attuned to their child's signals, quickly adapt to the changing environment, and respond appropriately to the child. For example, if the child is getting frustrated when they cannot figure out how a toy works, sensitive parents notice this frustration, and provide help that is appropriate to the child's developmental level. Thus, children may feel supported by their parents and are therefore more motivated to seek new challenges and explore their surroundings (Mills-Koonce et al., 2015). Previous research shows that sensitivity of mothers and fathers generally contributes to higher levels of cognitive skills (e.g., Bernier et al., 2010; Towe-Goodman et al., 2014).

Mothers, fathers, and grandparents may contribute uniquely to individual differences in child EF skills (e.g., Meuwissen \& Carlson, 2015). Three studies have investigated the roles of maternal and paternal sensitivity in relation to child EF ( $\mathrm{Li}$ et al., 2019; Lucassen et al., 2015; Towe-Goodman et al., 2014), and the results of these studies are inconsistent. Two of them support the unique role of maternal and paternal sensitivity in EF skills, concurrently at 14 months (Li et al., 2019) and over time from 24 months to 36 months (Towe-Goodman et al., 2014). Lucassen and colleagues (2015), however, only found a relation between maternal sensitivity and child EF, but not between paternal sensitivity and child EF at 4 years of age. In terms of grandparental effects on cognitive development, the systematic review showed that grandparental coresidence was beneficial for grandchildren's cognitive skills such as communication skills, language skills, and school achievement (Sadruddin et al., 2019). However, lower levels of grandparental socioeconomic status (SES) may negatively influence child cognitive development although sensitive-responsive parenting from parents may buffer the negative effect of low SES grandparents on child cognitive development (Lee et al., 2019). One study conducted in Taiwan showed that children in seventh grade who lived with long-term co-residing grandparents got the highest test scores compared to peers without co-residing grandparents (Pong \& Chen, 2010). To date, no studies have investigated the roles of mothers, fathers, and grandparents together in children's development in general, or EF development in particular.

\section{The Current Pilot Study}

The pilot study is part of a cross-cultural longitudinal study on the transition to parenthood among first-time mothers and fathers (e.g., Hughes et al., 2020) in relation to child development. The inclusion of grandparents was unique for the Chinese part of the study as co-residing grandparents are only common in China, and not the other countries in the study. The goal of the current study is to extend existing work on parenting and child EF by including mothers, fathers, and co-residing grandparents, and examine whether grandparental sensitivity relates to parental sensitivity (biological child of the grandparent), and whether grandparental sensitivity and maternal and paternal sensitivity each uniquely contribute to 14-month-old children's EF in 
China. We hypothesized that: (1) grandparental sensitivity is related to parental sensitivity towards 14-month-old children and (2) grandparental sensitivity and maternal and paternal sensitivity each uniquely contribute to child EF at 14 months.

\section{Method}

\section{Sample}

Participants participated in an international and longitudinal study that aims to examine which maternal and paternal characteristics before the birth of their first baby, and parenting processes during infancy predict the development of toddlers' cognitive skills. The larger study was conducted prenatally, at 4 months, 14 months, and 24 months of child age in the United Kingdom, the United States, and the Netherlands (e.g., Hughes et al., 2020). The Chinese part of the study was only conducted at 4 and 14 months. Sixtythree first-time mothers and fathers and their healthy 4month-old infants (51\% boys) were recruited at a maternity and child hospital, at yoga classes, and through online groups in urban Shenzhen, China. Both mother-infant and father-infant dyads were visited at home at 4 and 14 months of infant age. The inclusion criteria for participating parents were: (1) first-time parents; (2) 21 years or older during pregnancy (both parents); (3) had a singleton and full-term infant; (4) native Chinese speakers (Mandarin or Cantonese); (5) no history of any mental illness or substance abuse. The current study only used the data from the 14months wave, as we only have grandparental data available for this time point. Two mothers and six fathers did not participate at 14 months due to time limitations. One grandparent from each family who co-resided with parents and grandchildren at 14 months of infant age and spent the most time with the grandchild was invited to take part in the 14-months home visit. A total of 42 grandparents (out of 46 co-residing grandparents) agreed to participate in this study (19 maternal grandmothers; 20 paternal grandmothers; 3 paternal grandfathers). There were no differences in age, educational level, family income, maternal and paternal sensitivity between the 42 parents with participating grandparents and the other 21 parents (ps: 0.160-0.930). The data was collected between July, 2017 and February, 2018.

The average age of infants was 14.83 months $(S D=$ 1.16 , range $11.92-18.48$ months). $43 \%$ were boys. The average ages of mothers and fathers were 30 years $(S D=$ 2.59 , range $25-37$ years) and 31 years $(S D=3.14$, range 24-37 years) and the average age of grandparents was 56 years $(S D=4.65$, range $47-66$ years) when the infant was 14 months. Considering educational level, most of mothers
(76.0\%) and fathers (77.5\%) were highly educated (bachelor's degree or higher). Some mothers $(24.0 \%)$ and fathers $(18.0 \%)$ had a medium educational level (post-secondary or short-cycle tertiary education). None of the mothers and the rest of the fathers (4.5\%) had a low education (upper secondary degree or lower). None of the grandparents were highly educated, some (18.4\%) had medium educational level and most of them $(81.6 \%)$ had a low educational level. Most families had middle-to-upper income levels with around $16 \%$ higher income than the average level in Shenzhen (Shenzhen Statistics Bureau, 2018).

\section{Procedure}

Mothers and fathers were scheduled in two separate $2 \mathrm{~h}$ home visits. Grandparents participated in one of the two visits (counterbalanced between grandparents). The order of parent visits was also counterbalanced. An informed consent form was signed by all fathers, mothers and grandparents for their own participation as well as the infants' participation. A small infant gift and a small amount of money were given to all families as compensation after each home visit. Families also received a DVD with a compilation of video footage from different home visits at the end of the study. The study was approved by the Ethics Committee at Leiden University in the Netherlands and Shenzhen University in China.

Infants were tested in the first home visit (either the mother or the father visit). They completed a short battery of three EF tasks based on previous studies (Friedman et al., 2011; Miller \& Marcovitch, 2015; Hughes \& Ensor, 2005) in a fixed order: prohibition task, multi-location search task and ball run task. Infants sat on their parent's lap during the task. Parents were asked to remain silent and not give any verbal or behavioral instructions to infants. Infants had breaks and were praised after each task to maintain their interest in participating. If one of the tasks was not successful in the first home visit, that task was performed again during the next home visit with the other parent. After all infant tasks, the parent played with the infant with toys for $5 \mathrm{~min}$. The grandparent and the infant played with a new set of toys after the parent-infant interaction (either the mother or the father). Parents and grandparents completed questionnaires about background information after each home visit.

\section{Measures}

\section{Parent-infant and grandparent-infant interaction}

Parental and grandparental sensitivity were measured with the Ainsworth Sensitivity Scales (Ainsworth et al., 1974) 
during free play with toys $(5 \mathrm{~min})$. Mother-infant dyads, father-infant dyads, and grandparent-infant dyads were filmed separately. Sensitivity represents caregivers' ability to notice child's signals, interpret those signals correctly and give child-appropriate and prompt response and was rated on a 9 -point scale $(1=$ highly insensitive; $9=$ highly sensitive). All videos were coded by 4 independent coders (1 Chinese, 1 Dutch-Chinese, and 2 Dutch coders). English subtitles were used for non-Chinese speaking coders. The father, mother, and grandparent within one family were coded by three independent coders. A quarter of the videos were double coded for reliability. Intercoder reliabilities (interclass correlation, single rater, absolute agreement) were $>0.72$ for all coder pairs on all scales (mother-infant dyad $>0.72$; father-infant dyad $>0.78$; grandparent-infant dyad $>0.83$ ).

\section{Infant executive function at 14 months}

Inhibition (IB) The Prohibition Task (Friedman et al., 2011) was used to assess infants' inhibition ability. Infants were asked to resist touching a shiny glitter wand ('Mystic Glitter Wand'). The examiner first showed the wand for up to $15 \mathrm{sec}$ and got infants' attention. Then the examiner placed the wand within arm's reach of the infant, and gave an instruction "Look, <name child >. No, don't touch". After this, the examiner turned around for up to $30 \mathrm{sec}$. The camera was placed to capture the infant's face. Scores were calculated by the latency before touching the toy. Doublecoding of 60 of videos revealed high levels of inter- rater agreement, ICC $=0.99, p<0.001$.

Working memory (WM) The Multi-Location Search Task (Miller \& Marcovitch, 2015) was used for working memory. Infants were asked to search for three cars (i.e., red, yellow and, blue plastic cars) hidden in a toy garage with colored doors (i.e., red, yellow, and blue). The examiner first introduced the cars to the child and placed all cars into a color-corresponding garage (e.g., the blue car in the blue garage). The examiner blocked the child's view using a whiteboard $(29.7 \mathrm{~cm} \times 42 \mathrm{~cm})$ and counted out loud for $5 \mathrm{sec}$. After this, the examiner asked "where is the car". As all garages have cars, all infants were successful on the first trial. After infants pointed to one garage, the examiner took the car out and let the infant briefly play with the car and praised the infant. Then the examiner took the retrieved car from the infant and showed the infant that the car was being placed in a bag. Before the next trial, the examiner closed the empty garage. For the subsequent trials, if infants pointed to the empty garage, the examiner opened it and said "It's not there. Let's have another go" and closed the garage. The examiner stopped the task if the infant failed to find a toy car for three consecutive trials or when the infant retrieved all toy cars. The total number of cars that the infant successfully retrieved was coded $(0=$ retrieved 1 car, $1=$ retrieved 2 cars, 2 = retrieved 3 cars). Scoring took place offline and double-coding of 60 videos revealed excellent inter-rater reliability for each trial, Kappa $=1.00$.

Cognitive flexibility (CF) The Ball Run Task was designed as an age-appropriate shifting task measuring cognitive flexibility based on the Trucks Task developed by Hughes and Ensor (2005). There were three circular holes (i.e., green, yellow, red) in a row on the top of the adapted ball run toy. The middle yellow hole and either the green or red hole were closed by using two metal brackets. Infants were instructed to place either a red or green ball in the same colored and opened hole (e.g., place the red ball in the red hole or the green ball in the green hole) (counter-balanced across children) in the learning phase. If the infant scored four or more out of six trials (34\% infants), the examiner continued the task to reversal phase. Before this phase, the examiner took the ball they were using in the learning phase (e.g., the green ball) and placed it in a bag in view of the infant. The examiner then retrieved a different ball (e.g., the red ball) and closed the open hole (e.g., the green hole) while the infant was attracted to the toy and opened the closed hole (e.g., the red hole). The rule then changed to place another colored ball in the same colored hole (e.g., place read ball in red hole). Infants who failed to pass the learning phase (scored 4 or less) scored 0 . Infants received 1 point if they passed the learning phase and 2 points if they passed the reversal phase (scored four or more out of six trials). Scoring took place offline and double-coding of 60 videos revealed excellent inter-rater reliability for each trial, Kappa $=1.00$.

Consistent with findings from previous research (Devine et al., 2019; Miller \& Marcovitch, 2015), the threecomponent scores of EF were uncorrelated with one another $(r s<0.12, p s>0.47)$, suggesting EF in infancy is better represented by multiple components rather than one overarching component.

\section{Educational gap between parent and grandparent (control variable)}

Parental and grandparental educational level were measured on a 9-scale point: $0=$ early childhood, $1=$ primary education, $2=$ lower secondary education, $3=$ upper secondary education, $4=$ post-secondary education, $5=$ short-cycle tertiary education, $6=$ bachelor's or equivalent level, $7=$ master's or equivalent level, $8=$ doctoral or equivalent level. Educational differences between parents and grandparents were calculated by subtracting grandparental education from parental education. The higher the score, the higher educated the parent was compared to the grandparent. 


\section{Statistical Analysis}

We conducted our primary analyses using IBM SPSS 25.0. Descriptive statistics and bivariate correlations were carried out for all variables first. The percentage of missing data ranged from $0 \%$ (grandparental sensitivity) to $10 \%$ (educational gap between parents and grandparents). Multiple (20-fold) imputations were carried out for all missing values based on predictive mean matching which assumes that the missing values are missing at random (Van Buuren et al., 2006). Background information (child's gender and age, the age and education level of mothers, fathers and grandparents) and all the variables in the model were included in the imputation model. The multilevel regression coefficients and their standard errors were pooled in SPSS, using Rubin's combination rules (1987) which were carried out using a SPSS macro developed by Van Ginkel (2014). No outliers have been found for all variables (larger than 3.29 $S D$ above or below).

To address our research hypotheses, two sets of analyses were undertaken (see Fig. 1). Assuming a power of at least $80 \%$ and an alpha of 0.05 , a group size of 42 participants could only detect a medium to large effect size (e.g., $f^{2}=$ 0.3 ) for testing main effects with 3 predictors. In the first set, data of the biological child (mother or father of the child) of the grandparent (i.e., if maternal grandparent participated, the mother was selected; if paternal grandparent participated, the father was selected) was used to test the relation between parental sensitivity and grandparental sensitivity towards the grandchild using Pearson correlations. In total, 19 mothers and 23 fathers and their parent were included in this analysis. For the second set of analyses predicting infant $\mathrm{EF}$, data from all 42 infants, mothers, fathers, and grandparents were included. Pearson
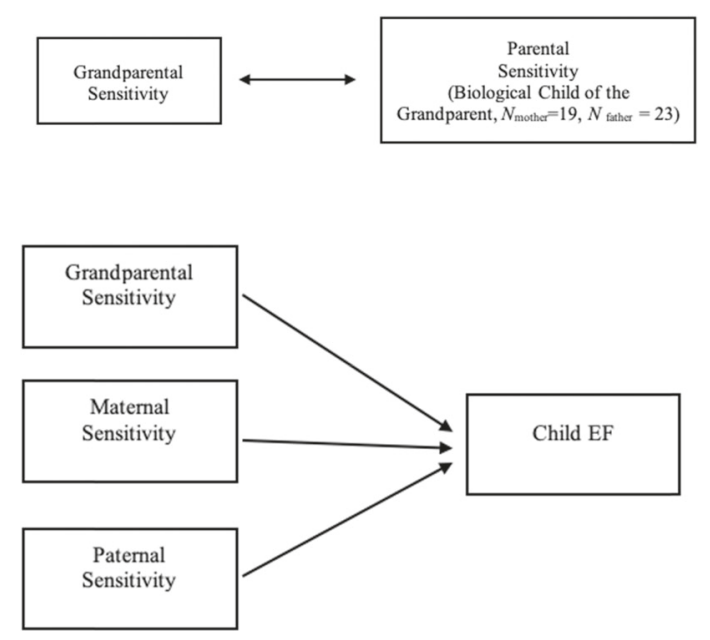

Fig. 1 Two Sets of Analyses. Analysis 1 The relation between grandparental sensitivity and parental sensitivity $(N=42)$. Analysis 2 Unique contribution of different caregivers in child $\mathrm{EF}(N=42)$ correlations were first used to test the relation between grandparental sensitivity, maternal sensitivity, and paternal sensitivity. To test whether grandparental sensitivity, maternal and paternal sensitivity uniquely predicted infant EF at 14 months, we used one hierarchical regression model (outcome: inhibition), two multinominal logistic regression models (outcome: working memory and cognitive flexibility). The reference group of these two models was the group that scored 0 on the task. As family socio-economic status (SES), child gender, and child age were not related to child outcomes, those variables were not controlled for.

\section{Results}

Descriptive statistics of and correlations between the main variables (both data sets) are presented in Table 1. The mean levels of maternal sensitivity and paternal sensitivity were 5.31 and 4.73, and for grandparental sensitivity it was 4.21. Maternal sensitivity was higher than grandparental sensitivity, $t(41)=-2.67, p=0.011, d=0.62$, but there were no significant differences between paternal sensitivity and grandparental sensitivity, $t(38)=-1.27, p=0.211$, or between maternal sensitivity and paternal sensitivity, $t(38)=1.66, p=$ 0.105 . The average difference in educational level between parents and grandparents was 4.28 (on a scale ranging from 0 to 8 ). In the Prohibition task, $15 \%$ of the infants did not touch the wand (waited for $30 \mathrm{~s}$ ). In the Multi-location Search task, $44 \%$ infants successfully retrieved 2 cars while a small number of them (20\%) retrieved 3 cars. In the Ball Run task, $53 \%$ infants failed both phases, $34 \%$ of them passed the learning phase and $13 \%$ of them passed the learning and reversal phases.

\section{The relation between grandparental sensitivity and parental sensitivity}

The pooled bivariate correlation between grandparental and parental sensitivity (biological child of the grandparent) was not significant $(r=0.09, p=0.590$; Table 1).

\section{Unique contribution of different caregivers in child EF}

The pooled bivariate correlations between variables were also examined first (Table 1). There were no significant correlations between grandparental sensitivity and maternal sensitivity $(r=-0.11, p=0.503)$, or between grandparental sensitivity and paternal sensitivity $(r=0.11, p=$ 0.512). Grandparental sensitivity was not correlated with infant inhibition $(p=0.117)$, working memory $(p=0.650)$ and cognitive flexibility $(p=0.125)$. Maternal sensitivity was significantly correlated with infant working memory 
Table 1 Descriptive Statistics and Correlations between Main Variables in China

\begin{tabular}{|c|c|c|c|c|c|c|c|c|c|c|c|}
\hline & & 1 & 2 & 3 & 4 & 5 & 6 & 7 & $M(\mathrm{SD})$ & Range & $N$ \\
\hline \multicolumn{12}{|c|}{ Intergenerational similarity of sensitivity } \\
\hline 1 & G1Sen & - & & & & & & & $4.21(1.93)$ & $1-8$ & 42 \\
\hline 2 & G2PSen & 0.09 & - & & & & & & $4.85(1.84)$ & $1-8$ & 42 \\
\hline \multicolumn{12}{|c|}{ Unique contribution of different caregivers to child EF } \\
\hline 3 & G1Sen & & & - & & & & & $4.21(1.93)$ & $1-8$ & 42 \\
\hline 4 & G2MSen & & & -0.11 & - & & & & $5.31(1.63)$ & $2-8$ & 42 \\
\hline 5 & G2FSen & & & 0.11 & 0.21 & - & & & $4.78(2.01)$ & $1-8$ & 42 \\
\hline 6 & Infant IB & & & 0.25 & -0.04 & -0.01 & - & & $6.74(11.47)$ & $0-35.56$ & 42 \\
\hline 7 & Infant WM & & & -0.07 & $0.36^{*}$ & 0.17 & -0.01 & - & $0.84(0.74)$ & $0-2$ & 42 \\
\hline 8 & Infant $\mathrm{CF}$ & & & 0.24 & 0.11 & -0.06 & -0.12 & 0.05 & $0.59(0.71)$ & $0-2$ & 42 \\
\hline
\end{tabular}

${ }^{*} p<0.05$, G1Sen Grandparent sensitivity, G2PSen Parental sensitivity (biological child of grandparent), G2MSen Mother sensitivity, G2FSen Father sensitivity, IB Inhibition, WM Working Memory, CF Cognitive Flexibility $(r=0.36, p=0.021)$ but not with inhibition $(p=0.821)$ and cognitive flexibility $(p=0.505)$, while paternal sensitivity was not significantly related to any infant EF abilities ( $p>0.305$ ). Next, one hierarchical regression model (outcome: inhibition) and two multinominal logistic regression models (outcome: working memory and cognitive flexibility) were performed to predict the three infant EF outcomes. All model details are presented in Table 2. Pooled results showed that neither the model for inhibition, working memory nor for cognitive flexibility was significant (IB: $F(3,36.14)=0.83, p=0.485$; WM: $F(6,164882.62)=$ $1.14, p=0.337$; CF: $F(6,23074.06)=0.81, p=0.560)$, although the relation between maternal sensitivity and working memory of the group scoring 2 was significant $(B=0.74, p=0.044)$ in the nonsignificant WM model. This means that based on the current design, grandparental sensitivity, maternal sensitivity and paternal sensitivity did not significantly contribute to infant EF abilities.

\section{Discussion}

The current pilot study investigated the relation between grandparental sensitivity and parental sensitivity (biological child of the grandparent) on child EF at 14 months and the unique impact of grandparental sensitivity, maternal and paternal sensitivity on child EF at 14 months in China. Our findings showed that: (1) grandparental sensitivity was not related to parental sensitivity; (2) grandparental sensitivity, maternal sensitivity, paternal sensitivity did not uniquely contribute to child EF at 14 months in the multivariate models, although bivariate correlation between maternal sensitivity and infant working memory was significant.

Contrary to our hypothesis, the relation between grandparental sensitivity and parental sensitivity was not significant, which means that there was no intergenerational
Table 2 Regressing grandparental sensitivity, maternal and paternal sensitivity on three EF outcomes

\begin{tabular}{|c|c|c|c|c|c|}
\hline \multicolumn{2}{|l|}{ Predictors } & $B$ & SE & $t$ & $p$ \\
\hline \multicolumn{6}{|c|}{ Model 1 (predicting infant inhibition) } \\
\hline \multicolumn{2}{|l|}{ Constant } & 1.64 & 8.03 & 0.20 & 0.839 \\
\hline \multicolumn{2}{|l|}{ Maternal sensitivity } & -0.01 & 1.13 & -0.01 & 0.991 \\
\hline \multicolumn{2}{|l|}{ Paternal sensitivity } & -0.21 & 0.94 & -0.22 & 0.822 \\
\hline \multicolumn{2}{|l|}{ Grandparental sensitivity } & 1.47 & 0.94 & 1.56 & 0.127 \\
\hline \multicolumn{6}{|c|}{ Model 2 (predicting infant working memory) 0 vs. } \\
\hline \multirow[t]{2}{*}{ Constant } & 1 & 0.21 & 1.68 & 0.12 & 0.902 \\
\hline & 2 & -5.94 & 2.81 & -2.12 & 0.034 \\
\hline \multirow[t]{2}{*}{ Maternal sensitivity } & 1 & 0.18 & 0.24 & 0.77 & 0.442 \\
\hline & 2 & 0.74 & 0.37 & $2.01 *$ & 0.044 \\
\hline \multirow[t]{2}{*}{ Paternal sensitivity } & 1 & -0.01 & 0.19 & -0.05 & 0.956 \\
\hline & 2 & -0.25 & 0.27 & -0.93 & 0.348 \\
\hline \multirow[t]{2}{*}{ Grandparental sensitivity } & 1 & -0.20 & 0.20 & -1.02 & 0.307 \\
\hline & 2 & -0.04 & 0.25 & -0.14 & 0.891 \\
\hline \multicolumn{6}{|c|}{ Model 3 (predicting infant cognitive flexibility) } \\
\hline \multirow[t]{2}{*}{ Constant } & 1 & -3.24 & 1.99 & -1.63 & 0.104 \\
\hline & 2 & -3.34 & 2.48 & -1.34 & 0.179 \\
\hline \multirow[t]{2}{*}{ Maternal sensitivity } & 1 & 0.41 & 0.28 & 1.50 & 0.134 \\
\hline & 2 & 0.17 & 0.33 & 0.50 & 0.614 \\
\hline \multirow[t]{2}{*}{ Paternal sensitivity } & 1 & -0.14 & 0.20 & -0.70 & 0.484 \\
\hline & 2 & -0.16 & 0.28 & -0.56 & 0.572 \\
\hline \multirow[t]{2}{*}{ Grandparental sensitivity } & 1 & 0.30 & 0.20 & 1.49 & 0.137 \\
\hline & 2 & 0.40 & 0.29 & 1.39 & 0.163 \\
\hline
\end{tabular}

$* p<0.05$. The reference group for model 2 and model 3 was the group which scored 0 on the task

similarity regarding sensitivity towards 14-month-old children in the current study. Moreover, we found that maternal sensitivity was higher than grandparental sensitivity. The level of paternal sensitivity was between the level of 
maternal and grandparental sensitivity, but was not significantly different from the other two. This result might be related to family and social changes in Chinese society. First, the massive growth in China's economy dramatically improved living conditions and increased the opportunities for Chinese society interacting with Western countries. The increased Western influence gives new generations exposure to Western values including more child-centered and supportive parenting styles. Contemporary urban Chinese parents regard happiness and good mental health (Xin $\mathrm{Li} \mathrm{Su}$ Zhi in Chinese) more important than "Excellence" (Youxiu in Chinese) (e.g., Way et al., 2013). Parents increasingly believe that raising autonomous children with high "qualities" such as social and communication skills are important for their success in this competitive world (Way et al., 2013), and research indeed shows that parental child-rearing attitudes and values are shifting (e.g., Cheung et al., 2016; Cheah et al., 2015). This may be one reason that G2 parents showed different levels of sensitive parenting towards G3 children compared to G1 grandparents. Second, the different childrearing attitudes and grandparental controlling behaviors in the family may be another possible explanation. In the past, grandparents, regardless of gender, had predominant roles with strong family power which required younger people to honor and obey grandparents (MjeldeMossey, 2007). In contemporary China, cultural traditions of the grandparental role are declining with less influential decision-making power (Tsui et al., 1996; Williams et al., 1999). Along with the economic development, social transformation and cultural change, there are significant generational gaps with regard to traditional values with younger generations having stronger sense of individualism, self-awareness and self-development than older generations (Sun and Wang, 2010). Family conflicts may arise if grandparents force traditions onto young parents. A survey of 1627 urban parents in China showed that more than half of the parents reported that the key challenge of grandparental joint caregiving was the differences in child-rearing methods (Goh \& Kuczynski, 2010). This is especially challenging if grandparents try to assert their power as the elders who should always be obeyed, and refuse to accept 'new' childrearing beliefs that the parents may hold. Those grandparents interfere in $\mathrm{G} 2$ parenting that can contribute to family conflict and tension (Hoang \& Kirby, 2020), and can result in insensitive grandparenting as power struggles are likely to disrupt sensitive care of G3 infants, and give way to controlling interactions.

Second, inconsistent with our hypothesis, grandparental sensitivity together with maternal and paternal sensitivity did not significantly predict child EF. There was one significant bivariate association between maternal sensitivity and infant working memory, but these associations did not hold in multivariate models. One possible explanation lies in the fact that the current sample size was underpowered to detect smaller effect sizes, so only the trend on this topic can be explored. Based on the previous research, maternal sensitivity contributes to the development of EF (e.g., Lucassen et al., 2015). Results from the current exploratory study regarding mother-infant dyads in China also point in this direction as the relation between maternal sensitivity and working memory of the group scoring 2 was significant in the nonsignificant model. Another possible explanation may be that in the current study we used a broad definition of sensitivity not specified to cognitive challenges, in a free play setting rather than in an EF-related task. A more cognitively stimulating situation such as completing a puzzle may be more likely to show differences in those aspects of sensitive responsiveness that are particularly relevant to EF development, such as autonomy support and scaffolding. However, because this is the first study to investigate maternal sensitivity, paternal sensitivity, and grandparental sensitivity together in relation to child $\mathrm{EF}$, relations between sensitivity of multiple caregiver and child $\mathrm{EF}$ remain an open question that needs to be examined further in larger samples.

To our knowledge, the current pilot study was the first observational study focusing on co-residing grandparents, mothers and fathers in relation to early child development in China. This multi-method study investigated the intergenerational similarity between grandparental and parental behaviors towards the third generation and explored the possible contributions of multiple caregivers on child selfregulation. There are some limitations for the present study. First, due to the recruitment difficulties, the limited time and financial support, only 42 parents and the co-residual grandparents were included in the current study. The small size reduced power for detecting smaller-sized effects (Hackshaw, 2008). Therefore, this study can only explore the trend on this topic instead of providing a solid conclusion. After this exploratory study, this topic should be further explored in a bigger sample size in future studies. Second, most of the families are from middle-to-high socioeconomic classes, which limited the possibility to investigate an association between parenting and child EF in a more vulnerable group such as families from lower socioeconomic status. Research has shown that those families are more likely to experience stress which may have an impact on parenting and child EF (e.g., Mesman et al., 2012). Third, sensitivity was measured in a general setting instead of a cognitive task. Although free play can and did certainly also evoke cognitive support in the form of showing a child how to use a new toy, the effect of sensitivity of multiple caregivers in a specific cognitive setting such as completing a puzzle task needs to be further investigated. Fourth, we only measured sensitivity of multiple caregivers separately with the infant. As grandparent and parent may also involve in playing or taking care of the 
infant at the same time, coparenting behaviors during triangular interactions can be further investigated.

In conclusion, the current pilot study did not find a significant relation between parental and grandparental sensitivity or a unique contribution of sensitivity from mothers, fathers and grandparents to infant EF. Our findings showed differences in sensitivity of grandparents and parents towards the third generation but did not confirm a combined effect of multiple caregivers on infant EF development in China. As early childhood lays an important foundation for future life, we hope this study was the first step to examine contributors of infant development in multigenerational families in different contexts especially in non-Western countries. The more we know about families in different countries, the better those families can be supported in culturally appropriate ways.

Acknowledgements This work is part of the research program "Origins of early individual differences in self-regulation: A multi-method study involving mothers, fathers and infants in the UK, the Netherlands and the US" with project number 464-13-141, which is partly financed by the Netherlands Organization for Scientific Research (NWO). Support from the China Scholarship Council (CSC) is gratefully acknowledged.

\section{Compliance with Ethical Standards}

Conflict of Interest The authors declare no competing interests.

Publisher's note Springer Nature remains neutral with regard to jurisdictional claims in published maps and institutional affiliations.

Open Access This article is licensed under a Creative Commons Attribution 4.0 International License, which permits use, sharing, adaptation, distribution and reproduction in any medium or format, as long as you give appropriate credit to the original author(s) and the source, provide a link to the Creative Commons license, and indicate if changes were made. The images or other third party material in this article are included in the article's Creative Commons license, unless indicated otherwise in a credit line to the material. If material is not included in the article's Creative Commons license and your intended use is not permitted by statutory regulation or exceeds the permitted use, you will need to obtain permission directly from the copyright holder. To view a copy of this license, visit http://creativecommons. org/licenses/by/4.0/.

\section{References}

Ainsworth, M. D. (1964). Patterns of attachment behavior shown by the infant in interaction with his mother. Merrill-Palmer Quarterly of Behavior and Development, 10(1), 51-58.

Ainsworth, M. D. S., Bell, S. M., \& Stayton, D. F. (1974). Infant-mother attachment and social development: Socialization as a product of reciprocal responsiveness to signals. In Richards, M. P. M. (Ed.), The integration of a child into a social world (pp. 99-135). London: Cambridge University Press.

Barnett, M. A., Scaramella, L. V., Neppl, T. K., Ontai, L., \& Conger, R. D. (2010). Intergenerational relationship quality, gender, and grandparent involvement. Family Relations, 59(1), 28-44. https:// doi.org/10.1111/j.1741-3729.2009.00584.x.

Belsky, J., Jaffee, S. R., Sligo, J., Woodward, L., \& Silva, P. A. (2005). Intergenerational transmission of warm-sensitive-stimulating parenting: A prospective study of mothers and fathers of 3year-olds. Child Development, 76(2), 384-396. https://doi.org/10. 1111/j.1467-8624.2005.00852.x.

Bernier, A., Carlson, S. M., \& Whipple, N. (2010). From external regulation to self-regulation: early parenting precursors of young children's executive functioning. Child Development, 81(1), 326-339. https://doi.org/10.1111/j.1467-8624.2009.01397.

Best, J. R., Miller, P. H., \& Naglieri, J. A. (2011). Relations between executive function and academic achievement from ages 5 to 17 in a large, representative national sample. Learning and Individual Differences, 21(4), 327-336. https://doi.org/10.1016/j.lindif. 2011.01.007.

Burnette, D., Sun, J., \& Sun, F. (2012). A comparative review of grandparent care of children in the U.S. and China. Ageing International, 38(1), 43-57. https://doi.org/10.1007/s12126-0129174-z.

Cabrera, N. J., Fagan, J., Wight, V., \& Schadler, C. (2011). Influence of mother, father, and child risk on parenting and children's cognitive and social behaviors. Child Development, 82(6), 1985-2005. https://doi.org/10.1111/j.1467-8624.2011.01667.

Cheah, C. S. L., Li, J., Zhou, N., Yamamoto, Y., \& Leung, C. Y. Y. (2015). Understanding Chinese immigrant and European American mothers' expressions of warmth. Developmental Psychology, 51(12), 1802-1811. https://doi.org/10.1037/a0039855.

Chen, F., Short, S. E., \& Entwisle, B. (2000). The impact of grandparental proximity on maternal childcare in China. Population Research and Policy Review, 19(6), 571-590.

Chen, F., Liu, G., \& Mair, C. A. (2011). Intergenerational ties in context: Grandparents caring for grandchildren in China. Social Forces, 90(2), 571-594. https://doi.org/10.1093/sf/sor012.

Chen, Z., Liu, R. X., \& Kaplan, H. B. (2008). Mediating mechanisms for the intergenerational transmission of constructive parenting. Journal of Family Issues, 29(12), 1574-1599. https://doi.org/10. 1177/0192513x08318968.

Cheung, C. S., Pomerantz, E. M., Wang, M., \& Qu, Y. (2016). Controlling and autonomy-supportive parenting in the United States and China: Beyond children's reports. Child Development, 87(6), 1992-2007. https://doi.org/10.1111/cdev.12567.

Conger, R. D., Belsky, J., \& Capaldi, D. M. (2009). The intergenerational transmission of parenting: Closing comments for the special section. Developmental Psychology, 45(5), 1276-1283. https://doi.org/10.1037/a0016911.

Devine, R. T., Ribner, A., \& Hughes, C. (2019). Measuring and predicting individual differences in executive functions at 14 Months: A longitudinal study. Child Development. https://doi. org/10.1111/cdev.13217.

Dunifon, R. (2012). The Influence of Grandparents on the Lives of Children and Adolescents. Child Development Perspectives, 7(1), 55-60. https://doi.org/10.1111/cdep.12016.

Feng, J., \& Zhang, X. (2017). Retirement and grandchild care in urban China. Feminist Economics, 24(2), 240-264. https://doi.org/10. 1080/13545701.2017.1370120.

Friedman, N. P., Miyake, A., Robinson, J. L., \& Hewitt, J. K. (2011). Developmental trajectories in toddlers' self-restraint predict individual differences in executive functions 14 years later: A behavioral genetic analysis. Developmental Psychology, 47(5), 1410 https://doi.org/10.1037/a0023750.

Goh, E. C. L., \& Kuczynski, L. (2010). "Only children" and their coalition of parents: Considering grandparents and parents as joint caregivers in urban Xiamen, China. Asian Journal of Social Psychology, 13(4), 221-231. https://doi.org/10.1111/j.1467839x.2010.01314.x. 
Hackshaw, A. (2008). Small studies: Strengths and limitations. European Respiratory Journal, 32(5), 1141-1143. https://doi.org/10. 1183/09031936.00136408.

He, Y., Liu, C., Chen, Y., Huang, J., \& Luo, R. (2020). Intergenerational transmission of parenting style in rural China and the mediation effect of Caregiver's mental health. Children and Youth Services Review, 117. https://doi.org/10.1016/j.childyouth. 2020.105319.

Hoang, N. P. T., \& Kirby, J. N. (2020). A meta-ethnography synthesis of joint care practices between parents and grandparents from Asian cultural backgrounds: Benefits and challenges. Journal of Child and Family Studies, 29(3), 605-619. https://doi.org/10. 1007/s10826-019-01553-y.

Hughes, C., \& Ensor, R. (2005). Executive function and theory of mind in 2 year olds: A family affair? Developmental Neuropsychology, 28(2), 645-668. https://doi.org/10.1207/ s15326942dn2802_5.

Hughes, C., \& Ensor, R. (2011). Individual differences in growth in executive function across the transition to school predict externalizing and internalizing behaviors and self-perceived academic success at 6 years of age. Journal of Experimental Child Psychology, 108(3), 663-676. https://doi.org/10.1016/j.jecp.2010.06. 005 .

Hughes, C., Devine, R. T., Mesman, J., \& Blair, C. (2020). Understanding the terrible twos: A longitudinal investigation of the impact of early executive function and parent-child interactions. Developmental Science, 23(6). https://doi.org/10.1111/desc. 12979.

Jiang J., Urban R., Wang H., Ted G., Lian G., \& Anna S. (2007). Influence of grandparents on eating behaviors of young children in Chinese three-generation families. Appetite, 48(3), 377-383. https://doi.org/10.1016/j.appet.2006.10.004.

Ko, P.-C., \& Hank, K. (2013). Grandparents caring for grandchildren in China and Korea: Findings from CHARLS and KLoSA. The Journals of Gerontology Series B: Psychological Sciences and Social Sciences, 69(4), 646-651. https://doi.org/10.1093/geronb/ gbt129.

Lee, D. B., Assari, S., Miller, A. L., Hsieh, H.-F., Heinze, J. E., \& Zimmerman, M. A. (2019). Positive Parenting Moderates the Effect of Socioeconomic Status on Executive Functioning: A Three-Generation Approach. Journal of Child and Family Studies, 28(7), 1878-1885. https://doi.org/10.1007/s10826-01901411-x.

Li, Q., Liang, F., Liang, W., Zhang, J., Niu, M., \& Han, Y. (2017). The influence of different caregivers on infant growth and development in China. Frontiers in Pediatrics, 5. https://doi.org/10.3389/ fped.2017.00243.

Li, X., \& Liu, Y. (2019). Parent-grandparent coparenting relationship, maternal parenting self-efficacy, and young children'ssocial competence in Chinese urban families. Journal of Child and Family Studies, 28(4), 1145-1153. https://doi.org/10.1007/ s10826-019-01346-3.

Li, Y., Cui, N., Kok, H. T., Deatrick, J., \& Liu, J. (2019). The relationship between parenting styles practiced by grandparents and children's emotional and behavioral problems. Journal of Child and Family Studies, 28(7), 1899-1913. https://doi.org/10.1007/ s10826-019-01415-7.

Liu, R. X. (2016). School bonding, peer associations, and self-views: The influences of gender and grandparent attachment on adolescents in Mainland China. Youth and Society, 48(4), 451-469. https://doi.org/10.1177/0044118x13496825.

Liu, R. X. (2019). Harsh parental discipline and delinquency in Mainland China: The conditional influences of gender and bonding to paternal grandparents. Sociological Focus, 52(4), 274-291. https://doi.org/10.1080/00380237.2019.1668320.
Livesey, D., Keen, J., Rouse, J., \& White, F. (2006). The relationship between measures of executive function, motor performance and externalising behaviour in 5- and 6-year-old children. Human Movement Science, 25(1), 50-64. https://doi.org/10.1016/j. humov.2005.10.008.

Lucassen, N., Kok, R., Bakermans-Kranenburg, M. J., Van Ijzendoorn, M. H., Jaddoe, V. W., Hofman, A., \& Tiemeier, H. (2015). Executive functions in early childhood: The role of maternal and paternal parenting practices. British Journal of Developmental Psychology, 33(4), 489-505. https://doi.org/10.1111/bjdp.12112.

Luo, Y., Qi, M., Huntsinger, C. S., Zhang, Q., Xuan, X., \& Wang, Y. (2020). Grandparent involvement and preschoolers' social adjustment in Chinese three-generation families: Examining moderating and mediating effects. Children and Youth Services Review, 114(19). https://doi.org/10.1016/j.childyouth.2020. 105057.

Mesman, J., \& Emmen, R. A. G. (2013). Mary Ainsworth's legacy: A systematic review of observational instruments measuring parental sensitivity. Attachment \& Human Development, 15(5-6), 485-506. https://doi.org/10.1080/14616734.2013.820900.

Mesman, J., van IJzendoorn, M. H., \& Bakermans-Kranenburg, M. J. (2012). Unequal in opportunity, equal in process: Parental sensitivity promotes positive child development in ethnic minority families. Child Development Perspectives, 6(3), 239-250. https:// doi.org/10.1111/j.1750-8606.2011.00223.x.

Meuwissen, A. S., \& Carlson, S. M. (2015). Fathers matter: The role of father parenting in preschoolers' executive function development. Journal of Experimental Child Psychology, 140, 1-15. https:// doi.org/10.1016/j.jecp.2015.06.010.

Miller, S. E., \& Marcovitch, S. (2015). Examining executive function in the second year of life: Coherence, stability, and relations to joint attention and language. Developmental Psychology, 51(1), 101-114. https://doi.org/10.1037/a0038359.

Mills-Koonce, W. R., Willoughby, M. T., Zvara, B., Barnett, M., Gustafsson, H., \& Cox, M. J., Family Life Project Key Investigators. (2015). Mothers' and fathers' sensitivity and children's cognitive development in low-income, rural families. Journal of Applied Developmental Psychology, 38, 1-10. https://doi.org/10. 1016/j.appdev.2015.01.001.

Miyake, A., Friedman, N. P., Emerson, M. J., Witzki, A. H., Howerter, A., \& Wager, T. D. (2000). The unity and diversity of executive functions and their contributions to complex "Frontal Lobe" Tasks: A latent variable analysis. Cognitive Psychology, 41(1), 49-100. https://doi.org/10.1006/cogp.1999.0734.

Mjelde-Mossey, L. A. (2007). Cultural and demographic changes and their effects upon the traditional grandparent role for Chinese elders. Journal of Human Behavior in the Social Environment, 16 (3), 107-120. https://doi.org/10.1300/10911350802107785.

Müller, U., Jacques, S., Brocki, K., \& Zelazo, P. D. (2009). The executive functions of language in preschool children. In A. Winsler, C. Fernyhough, \& I. Montero (Eds.), Private speech, executive functioning, and the development of verbal selfregulation (pp. 53-68). Cambridge University Press. https://doi. org/10.1017/CBO9780511581533.005.

Nyland, B., Zeng, X., Nyland, C., \& Tran, L. (2009). Grandparents as educators and carers in China. Journal of Early Childhood Research, 7(1), 46-57. https://doi.org/10.1177/ 1476718x08098353.

Pong, S. L., \& Chen, V. W. (2010). Co-resident grandparents and grandchildren's academic performance in Taiwan. Journal of Comparative Family Studies, 41(1), 111-139. https://doi.org/10. 3138/jcfs.41.1.111.

Rubin, D. B. (1987). Multiple imputation for nonresponse in surveys. New York: Wiley.

Sadruddin, A. F. A., Ponguta, L. A., Zonderman, A. L., Wiley, K. S., Grimshaw, A., \& Panter-Brick, C. (2019). How do grandparents 
influence child health and development? A systematic review. Social Science and Medicine, 239. https://doi.org/10.1016/j. socscimed.2019.112476.

Shenzhen Statistics Bureau. (2018). Shenzhen statistical yearbook 2018. Retrieved November 24, 2020, from http://tjj.sz.gov.cn/zw gk/zfxxgkml/tjsj/tjnj/201812/P020181229639722485550.pdf.

Sulik, M. J., Haft, S. L., \& Obradović, J. (2018). Visual-motor integration, executive functions, and academic achievement: concurrent and longitudinal relations in late elementary school. Early Education and Development, 29(7), 956-970. https://doi.org/10. 1080/10409289.2018.1442097.

Sun, J., \& Wang, X. (2010). Value differences between generations in China: a study in Shanghai. Journal of Youth Studies, 13(1), 65-81. https://doi.org/10.1080/13676260903173462.

The World Bank (2018). Labor force participation rate, female-China. https://data.worldbank.org/indicator/SL.TLF.CACT.FE.ZS?loca tions $=\mathrm{CN}$.

Towe-Goodman, N. R., Willoughby, M., Blair, C., Gustafsson, H. C., Mills-Koonce, W. R., \& Cox, M. J. (2014). Fathers' sensitive parenting and the development of early executive functioning. Journal of Family Psychology, 28(6), 867-876. https://doi.org/ 10.1037/a0038128.

Tsui, M., Huang, H., \& He, Q. (1996). The decision making power of elderly women and men in the Chinese urban family. Asian Thought and Society, 21, 127-146.

Van Buuren, S., Brand, J. P. L., Groothuis-Oudshoorn, C. G. M., \& Rubin, D. B. (2006). Fully conditional specification in multivariate imputation. Journal of Statistical Computation and Simulation, 76(12), 1049-1064. https://doi.org/10.1080/ 10629360600810434.

Van Ginkel, J. R. (2014). SPSS syntax for applying rules for combining multivariate estimates in multiple imputation. Leiden University.
Wang, L., Emmen, R. A. G., \& Mesman, J. (2019). Beliefs about sensitive parenting among Chinese cross-generational caregivers: The mediating role of education. The International Journal of Aging and Human Development, 90(4), 385-402. https://doi.org/ 10.1177/0091415019836103.

Way, N., Okazaki, S., Zhao, J., Kim, J. J., Chen, X., Yoshikawa, H., \& Deng, H. (2013). Social and emotional parenting: Mothering in a changing Chinese society. Asian American Journal of Psychology, 4(1), 61-70. https://doi.org/10.1037/a0031204.

Williams, L., Mehta, K., \& Lin, H. S. (1999). Intergenerational influence in Singapore and Taiwan: The role of theelderly in family decisions. Journal of Cross-Cultural Gerontology, 14(4), 291-322.

Xing, S., Zhou, Q., Archer, M., Yue, J., \& Wang, Z. (2016). Infant temperamental reactivity, maternal and grandparental sensitivity: Differential susceptibility for behavior problems in China. Early Human Development, 101, 99-105. https://doi.org/10.1016/j.ea rlhumdev.2016.08.014.

Yeh, K.-H., Yi, C.-C., Tsao, W.-C., \& Wan, P.-S. (2013). Filial piety in contemporary Chinese societies: A comparative study of Taiwan, Hong Kong, and China. International Sociology, 28(3), 277-296. https://doi.org/10.1177/0268580913484345.

Zelazo, P. D., Carter, A., Reznick, J. S., \& Frye, D. (1997). Early development of executive function: A problem-solving framework. Review of General Psychology, 1(2), 198-226. https://doi. org/10.1037/1089-2680.1.2.198.

Zeng, Z., \& Xie, Y. (2014). The effects of grandparents on children's schooling: Evidence from rural China. Demography, 51(2), 599-617. https://doi.org/10.1007/s13524-013-0275-4.

Zhai, F., \& Gao, Q. (2010). Center-based care in the context of onechild policy in China: Do child gender and siblings matter? Population research and policy review, 29(5), 745-774. 